\title{
MOTILITAS DAN VIABILITAS SPERMATOZOA SAPI RAMBON DI DESA KEMIREN BANYUWANGI
}

\author{
Motility and Viability of Rambon Cattle Spermatozoa in Kemiren Village Banyuwangi \\ Zeni Prastika $^{1 *}$, Suherni Susilowati ${ }^{2}$, Bodhi Agustono $^{3}$, Erma Safitri $^{2}$, Faisal Fikri ${ }^{4}$, \\ Ragil Angga Prastiya ${ }^{2}$ \\ ${ }^{1}$ Mahasiswa Pendidikan Dokter Hewan, \\ ${ }^{2}$ Departemen Reproduksi Veteriner, \\ ${ }^{3}$ Departemen Peternakan, \\ ${ }^{4}$ Departemen Kedokteran Dasar Veteriner, \\ Fakultas Kedokteran Hewan, Universitas Airlangga, \\ Kampus C Mulyorejo, Surabaya, Jawa Timur, Indonesia, 60115 \\ Telp. (031)5993016, Fax. (031)5993015 \\ *Corresponding author: zeni.prastika-2014@fkh.unair.ac.id
}

\begin{abstract}
Abstrak
Sapi Rambon merupakan salah satu sapi lokal Indonesia. Tahun 2017 populasi sapi Rambon mengalami penurunan. Salah satu upaya pelestarian sapi lokal adalah melalui peningkatan populasi sapi dan inseminasi buatan. Faktor penentu keberhasilan perkawinan salah satunya adalah libido tinggi dan kualitas semen. Motilitas spermatozoa dan viabilitas spermatozoa adalah salah satu indikator fertilitas spermatozoa dan kualitas semen. Penelitain ini adalah penelitian deskriptif. Penelitian ini bertujuan untuk mengetahui motilitas dan viabilitas semen segar sapi Rambon di Desa Kemiren Kecamatan Glagah Kabupaten Banyuwangi. Semen pada penelitian ini di tampung menggunakan vagina buatan dari 6 ekor sapi Rambon jantan. Pemeriksaan motilitas spermatozoa dan viabilitas spermatozoa dilakukan di klinik Linawati Banyuwangi. Hasil pada penelitian ini disajikan dalam bentuk tabel. Parameter penelitian ini adalah motilitas dan viabilitas spermatozoa sapi Rambon. Hasil pemeriksaan motilitas spermatozoa sapi Rambon 83,3 $\pm 4,1 \%$ dan viabilitas spermatozoa sapi Rambon $86,7 \pm 2,3 \%$. Kesimpulan dari penelitian menunjukan bahwa motilitas dan viabilitas spermatozoa sapi Rambon baik dan memenuhi syarat semen beku untuk inseminasi buatan.
\end{abstract}

Kata kunci: Sapi Rambon, motilitas, viabilitas, spermatozoa

\section{Abstract}

Rambon is one of the Indonesia cattle. In 2017 the population of Rambon cattle were decreased. One of the efforts local cattle conservation was through increased population and artificial insemination. Determinant factor of mating one of them were high libido and cement quality. Sperm motility and sperm viability is one of indicator sperm fertility and cement quality. This study was descriptive. The aim of this study to identify sperm motility and viability of fresh semen Rambon cattle in Kemiren village Glagah subdistrict Banyuwangi district. Semen was collected using artificial vagina from six Rambon cattle. An examination of sperm motility and sperm viability did in Linawati Banyuwangi clinic. This study was describe in table. Parameter observed were sperm motility and sperm viability. The result showed that sperm motility $83,3 \pm 4,1 \%$ and sperm viability $86,7 \pm 2,3 \%$. In conclusion of sperm motility and sperm viability of Rambon Cattle were good and deserved to be frozen semen for insemination.

Key words: Rambon cattle, motility, viability, spermatozoa

\section{PENDAHULUAN}

Sapi Rambon adalah salah satu sapi lokal Indonesia selain sapi Bali, sapi Madura, sapi Rancah, sapi Jabres dan sapi Galekan (Sutarno and Setyawan, 2016). Sapi lokal Indonesia memiliki kemampuan adaptasi yang baik pada lingkungan iklim tropis di Indonesia, tahan terhadap penyakit tropis, memiliki daya reproduksi yang baik, tahan pada parasit lokal dan tahan terhadap pakan kualitas yang rendah (Agustar dan Jawandi, 2006; Sutarno dan Setyawan, 2015). 
Kabupaten Banyuwangi adalah salah satu daerah yang mengembangkan sapi Rambon khususnya Kecamatan Glagah (BPS Banyuwangi, 2015; Dispet Bayuwangi, 2005). Jumlah populasi sapi Rambon jantan di Kecamatan Glagah telah mengalami penurunan dari 183 ekor pada tahun 2005 menjadi 115 ekor pada tahun 2017 (Dispet Banyuwangi, 2005; Disper Banyuwangi, 2017). Penurunan populasi ternak lokal yang terus-menerus tiap tahun dapat menyebabkan ternak lokal terancam punah. Salah satu upaya untuk melestarikan ternak lokal adalah melalui peningkatan populasi ternak dengan pemanfaatan teknologi inseminasi buatan (Zulyazaini dkk., 2016).

Faktor yang berpengaruh terhadap keberhasilan perkawinan adalah tersedianya pejantan unggul, memiliki libido tinggi dan menghasilkan kualitas semen yang baik (Toelihere, 2000). Motilitas adalah daya gerak spermatozoa untuk membuahi sel telur (Wahyuningsih dkk., 2013). Daya gerak yang progresif sangat diperlukan spermatozoa saat di saluran kelamin betina untuk mencapai tempat fertilisasi (Sarastina dkk., 2012).

Motilitas merupakan salah satu indikator penting dalam menentukan kualitas semen dan keberhasilan fertilitas (Zulyazaini dkk., 2016). Viabilitas adalah daya hidup spermatozoa. Pemeriksaan viabilitas spermatozoa dapat dijadikan indikator integritas struktur membran spermatozoa (Sukmawati dkk., 2014). Viabilitas memiliki korelasi dengan motilitas yang ditentukan oleh kekuatan membran plasma spermatozoa (Azzahra dkk., 2016).

Berdasarkan latar belakang diatas perlu dilakukan penelitian mengenai identifikasi motilitas dan viabilitas spermatozoa sapi Rambon sebagai dasar penelitian sapi dan penerapan teknologi pengolahan semen dalam upaya pelestarian ternak lokal.

\section{METODE PENELITIAN}

Metode pada penelitian ini adalah eksploratif laboratoris. Data yang diperoleh disajikan dalam bentuk deskriptif. Sampel pada penelitian ini adalah 6 ekor sapi Rambon jantan. Pengambilan sampel dilakukan di Desa Kemiren Kecamatan Glagah Kabupaten Banyuwangi. Penampungan semen dilakukan menggunakan vagina buatan kemudian dilakukan pemeriksaan makroskopis yang meliputi volume, bau, warna, $\mathrm{pH}$ dan konsistensi semen di klinik Linawati Banyuwangi. Pemeriksaan motilitas dan viabilitas dilakukan di laboratorium klinik Linawati Banyuwangi.

Pemeriksaan motilitas spermatozoa dilakukan pada semen segar sapi Rambon yang di tampung menggunakan vagina buatan. Pemeriksaan motilitas dilakukan pada semen yang diencerkan dengan $\mathrm{NaCl}$ fisiologis kemudian diamati dibawah mikroskop Olympus ${ }^{\circledR}$ CX23 perbesaran 400X (Susilowati dkk., 2010).

Pemeriksaan viabilitas spermatozoa dilakukan dengan membuat preparat ulas tipis menggunakan pewarnaan eosin-negrosin yang kemudian diamati dengan mikroskop Olympus ${ }^{\circledR}$ CX23 perbesaran 1000X. Spermatozoa yang hidup tidak akan terwarnai oleh zat warna, sedangkan spermatozoa yang mati akan terwarnai. Spermatozoa yang mati berwarna merah keunguan dan yang hidup berwarna putih tanpa warna (Susilowati dkk., 2010).

\section{HASIL DAN PEMBAHASAN}

Hasil pemeriksaan motilitas dan viabilitas 6 sampel semen segar sapi Rambon di Desa kemiren Kecamatan Glagah Kabupaten Banyuwangi disajikan pada tabel 1.

Tabel 1. Pemeriksaan motilitas dan viabilitas

\begin{tabular}{rcc}
\hline Sampel & Motilitas (\%) & Viabilitas (\%) \\
\hline Sapi 1 & 85 & 86 \\
Sapi 2 & 80 & 87 \\
Sapi 3 & 90 & 90 \\
Sapi 4 & 80 & 86 \\
Sapi 5 & 85 & 88 \\
Sapi 6 & 80 & 83 \\
Mean \pm SD & $83,3 \pm 4,1$ & $86,7 \pm 2,3$ \\
\hline Motilitas & adalah daya gerak spermatozoa \\
yang dapat & dijadikan sebagai acuan dalam \\
penilaian kualitas spermatozoa untuk inseminasi \\
buatan (Bintara, 2011). Hasil penelitian motilitas \\
spermatozoa & sapi Rambon adalah $80 \%-90 \%$
\end{tabular}


dengan rata-rata $83,3 \pm 4,1 \%$. Hasil tersebut tidak jauh berbeda dengan motilitas individu spermatozoa sapi Bali 88,7\% (Ratnawati dkk., 2008), individu motlitas sapi Peranakan Ongole 85\% (Pratiwi dkk., 2007) dan motilitas individu sapi Madura 73\% (Ramadhoni dkk., 2014). Menurut Garner and Hafez (2000) motilitas spermatozoa sapi berkisar antara 40-75\%, syarat dilakukan semen yang diencerkan atau semen beku memiliki motilitas spermatozoa minimal $70 \%$.

Menurut Susilowati dkk., (2010) motilitas spermatozoa sapi pada pejantan yang fertil adalah $50-80 \%$ dan bergerak progresif. Perbedaan motilitas spermatozoa dapat disebabkan oleh umur pada sapi Peranakan Ongole umur 1,5 tahun memiliki motilitas lebih rendah dibandingakn dengan umur 2 tahun, hal ini karena pada sapi umur 2 tahun organ reproduksi primer dan sekunder sudah optimal (Azzahra dkk., 2016).

Ketersediaan sumber energi spermatozoa dari plasma semen berupa fruktosa, sorbitol, plasmogen dan glyceryphosporil choline juga dapat mempengaruhi motilitas spermatozoa (Aerens, 2012; Sundari dkk., 2013). Menurut Herdis (2005) menyatakan bahwa motilitas spermatozoa dipengaruhi oleh perbedaan bangsa ternak dan waktu pemeriksaan. Faktor lain yang dapat mempengaruhi motilitas adalah pakan (Zulfan, 2008).

Viabilitas adalah daya hidup spermatozoa sebagai indikator kualitas spermatozoa (Sukmawati dkk., 2014). Hasil pemeriksaan viabilitas spermatozoa sapi Rambon yaitu $83 \%$ $90 \%$ dengan rata-rata $86,7 \pm 2,3 \%$. Viabilitas sapi Rambon tidak jauh berbeda dengan sapi Bali $86,75 \%$ (Rizal, 2009), viabilitas spermatozoa sapi Madura 85\% (Ratnawati dkk., 2017) dan viabilitas spermatozoa sapi Peranakan Ongole 97\% (Pratiwi dkk., 2007).

Viabilitas spermatozoa untuk pembutan semen yang diencerkan atau semen beku minimal memiliki $60 \%$ sampai $75 \%$ spermatozoa hidup (Garner and Hafez, 2000). Presentase hidup spermatozoa ditentukan oleh membran plasma yang utuh. Membran plasma spermatozoa berfungsi untuk melindungi organel spermatozoa dan transport elektrolit untuk metabolisme spermatozoa (Salmah, 2014). Membran plasma yang rusak dapat berpengaruh fungsi fisiologis dan metabolisme spermatozoa sehingga menyebabkan spermatozoa mati (Butarbutar, 2009).

Metabolisme spermatozoa dapat mempengaruhi daya hidup spermatozoa karena pada spermatozoa yang memiliki aktivitas metabolisme tinggi mengahasilkan asam laktat yang tinggi yang dapat membunuh spermatozoa (Varasofiari dkk., 2013). Membran plasma yang utuh memiliki kolerasi dengan motilitas spermatozoa, semakin banyak membran plasma spermatozoa yang utuh maka semakin banyak spermatozoa yang motil (Azzahra dkk., 2016). Kualitas spermatozoa dikatakan baik jika memiliki jumlah spermatozoa hidup tinggi dan spermatozoa mati < 15\% (Bintara, 2011).

\section{KESIMPULAN}

Semen sapi Rambon memiliki kualitas yang baik memenuhi syarat kelayakan untuk di proses menjadi semen yang diencerkan atau semen beku program inseminasi buatan.

\section{UCAPAN TERIMA KASIH}

Peneliti mengucapkan terima kasih kepada Dinas Pertanian Kabupaten Banyuwangi atas izin yang diberikan untuk melakukan penelitian.

\section{DAFTAR PUSTAKA}

Aerens, C.D., M.N. Ihsan dan N. Isnaini. 2012. Perbedaan Kuantitatif dan Kualitatif Semen Segar pada Berbagai Bangsa Sapi Potong. Malang. 1-10.

Agustar, A. dan Jaswandi. 2006. Menilirik Potensi Sapi Lokal dalam Upaya Mewujudkan Kecukupan Pangan dan Pengembangan Kawasan Pembangunan Peternakan. Fakultas Peternakan Universitas Andalas. 21-30. 
Azzahra, F.Y., E.T. Setiatin dan D. Samsudewa. 2016. Evaluasi Motilitas dan Pesentase Hidup Semen Segar Sapi PO Kebumen Pejantan Muda. Fakultas Peternakan dan Pertanian Universitas Diponegoro. Semarang. Jurnal Sains Peternakan Indonesia, (2):99-107.

Badan Pusat Statistik Kabupaten Banyuwangi. 2015. Statistik Daerah Kecamatan Glagah 2015. Banyuwangi.

Bintara, S. 2011. Rasio X:Y dan Kualitas Sperma pada Kambing Kacang dan Peranakan Ettawa. Fakultas Peternakan Universitas Gadjah Madda. Yogyakarta. Sains Peternakaan, 9(2):65-71.

Butarbutar, E. 2009. Efektifitas Frekuensi Exercise Terhadap Peningkatan Kualitas Semen Sapi Simmental [Skripsi]. Fakultas Pertanian Universitas Sumatra Utara. Hal 23-50.

Dinas Pertanian Kabupaten Banyuwangi. 2017. Rekap Populasi Ternak Per Wilayah (ekor). Dinas Pertanian Kabupaten Banyuwangi. Banyuwangi.

Dinas Peternakan Kabupaten Banyuwangi. 2005. Populasi Sapi Rambon di Kecamatan Glagh Kabupaten Banyuwangi Tribulan III 2005. Dinas Peternakan Kabupaten Banyuwangi. Banyuwangi.

Garner D.L. and E.S.E. Hafez. 2000. Spermatozoa and Seminal Plasma. In: E. S. E. Hafez (Ed.). Reproduction in Farm Animal. $7^{\text {th }}$. ed. Lippomcott Wiliams and wilkins. Philadelphia. 96-106.

Herdis. 2005. Optimalisasi Inseminasi Buatan Melalui Aplikasi Teknologi Laserpuntur pada Domba Garut (Ovis aries) [Disertasi]. Institut Pertanian Bogor. Bogor. Hal. 41-50.

Pratiwi, W.C., L. Affandhy dan P. Situmorang. 2007. Observasi Kualitas Semen Cair Sapi
Peranakan Ongole terhadap Perbedaan Waktu Inkubasi pada Proses Pemisahan Spermtozoa. 2007. Loka Penelitian Sapi

Potong. Bogor. 195-200.

Ramadhoni, I., A. Rachmawati dan Suyadi. 2014. Kualitas Semen Sapi Madura Setelah Pengenceran dengan Tris Aminomethane Kuning Telur yang disuplementasi $\alpha$ tocopherol pada Penyimpanan Suhu Ruangan. Fakultas Peternakan Universitas Brawijaya. Malang. Jurnal Ilmu-ilmu Peternakan, 24(1):39-44.

Ratnawati, D., L. Affandhy, W.C. Pratiwi dan P. W. Prihandini. 2008. Pengaruh Pemberian Suplemen Tradisional Terhadap Kualitas Semen Pejantan Sapi Bali. Loka Penelitian Sapi Potong. 116-121.

Ratnawati, D., N. Isnaini dan T. Susilawati. 2017. Pemanfaatan casa dalam Observasi Motilitas Spermatozoa Semen Cair Sapi Madura dalam Pengencer yang Berbeda. Jurnal Ilmu-ilmu Peternakan, 27(1):80-95.

Rizal, M. 2009. Daya Hidup Spermatozoa Epididimis Sapi Bali yang Dipreservasi pada Suhu $3-5^{\circ} \mathrm{C}$ dalam Pengencer Tris dengan Konsentrasi Laktosa yang berbeda. Fakultas Peternakan Universitas Pattimura. Ambon. JITV, 14(2):142-149.

Salmah, N. 2014. Motilitas, Presentase Hidup dan Abnormalitas Spermatozoa Semen Beku Sapi Bali pada Pengenceran Andromed dan Tris Kuning Telur [Skripsi]. Fakultas Peternakan Unversitas Hasanuddin. Makassar. Hal 37-38.

Sukmawati, E., R.I. Arifiantini dan B. Purwantara. 2014. Daya Tahan Spermatozoa Terhadap Proses Pembekuan Pada Berbagai Jenis Pejantan Unggul. Fakultas Kedokteran Hewan, Institut Pertanian Bogor. JITV, 19(3):168-175. 
Sarastina, T. Susilawati dan G. Ciptadi. 2012. Analisi Beberapa Parameter Motilitas Spermatozoa pada Berbagai TernakMenggunakan Computer Assisted Semen Analysis (CASA). Jurnal Ternak Troika, 6(2):1-12.

Sukmawati, E., R.I. Arifiantini dan B. Purwantara. 2014. Daya Tahan Spermatozoa Terhadap Proses Pembekuan pada Berbagai Jenis Sapi Pejantan Unggul. Fakultas Kedokteran Hewan Institut Pertanian Bogor. JITV, 19(3):168-175.

Sundari, T.W., T.R. Tagama dan Maidaswar. 2013. Kolerasi Kadar pH Semen Segar dengan Kualitas Semen Sapi Limousin di Balai Inseminasi Buatan Lembang. Fakultas Peternakan Universitas Jenderal Soedirman. Purwokerto. Jurnal Ilmiah Peternakan, 1(3):1043-1049.

Susilowati, S., Hardijanto, T.W. Suprayogi, T. Sarjito, dan T. Hermawati. 2010. Petunjuk Praktikum Inseminasi Buatan.Airlangga University Press. Surabaya. Hal 5-37.

Sutarno and A.D. Setyawan. 2015. Genetic Deversity of Lokal and Exotic Cattle and Their Crossbreeding Impact on The Quality of Indonesia Cattle. Departemen of Biology. Fakulty of Mathematics and Natural Science Universtas Sebelas Maret. Biodiversitas, 16(2):327-354.

Sutarno and A.D. Setyawan. 2016. The Diversity of Lokal Cattle in Indonesia and The Efforts To Develop Superior Indigeneus Cattle
Breeds. Departemen of Biology. Faculty of Mathematicts and Natural Science Universitas Sebelas Maret. Biodiversitas, 17(1):275-295.

Toelihere. M.R. 2000. Inseminasi Buatan Pada Ternak. Penerbit Angkasa Bandung. Hal 4660:64-72.

Varasofiari, L.N., E.T. Setiatin, dan Sutopo. 2013. Evaluasi Kualitas Semen Segar sapi Jawa Brebes Berdasarkan Lama Waktu Penyipanan. Fakultas Peternakan dan Pertanian Universitas Diponegoro. Semarang. Animal Agriculture, 2(1):201208.

Wahyuningsih, A., D.M. Saleh dan Sugiyanto. 2013. Pengaruh Umur Pejantan dan FrekuensiPenampungan Terhadap Volumedan Motilitas Semen Segar Sapi Simmental di Balai Inseminasi Buatan Lembang. Fakultas Peternakan Universitas Jendral Soedirman. Jurnal Ilmiah Peternakan, 1(3):947-953.

Zulfan, M. 2008. Hubungan Antara Libido dengan Kualitas Semen Segar pada Pejantan Bos taurus. Fakultas Sains dan Teknologi. Universitas Islam Negeri Malang. Malang. Hal. 27-34.

Zulyazaini, Dasrul, S. Wahyuni, M. Akmal dan M.A.N. Abdullah. 2016. Karakteristik Semen dan Komposisi Kimia Plasma Seminaslis Sapi Aceh yang Diperihara di BIBD Saree Aceh Besar. Fakultas Kedokteran Hewan Universitas Syiah Kuala. Agripet, 16(2):121-130. 